\section{Hair analysis for drugs in child abuse}

\author{
Arlene Boroda MBBCh FRCPH ${ }^{1} \quad$ Wendy Gray MBChB ${ }^{2}$
}

J R Soc Med 2005;98:318-319

Testing of blood and urine for drugs is limited by the narrow time scale in which substances and their metabolites can be detected. Hair analysis not only can detect substances taken a week to several months previously but also can be used to estimate the time of exposure. Hair analysis has been reported in a small number of cases of suspected child abuse. ${ }^{1-5}$

\section{CASE HISTORY}

Social services received anonymous information that a $3 \frac{1}{2}$ year-old boy and his 8-month-old sister had been given methadone regularly to facilitate sleep. The children were removed by the police and social services and placed 'in care'. An Emergency Protection Order was obtained, instructing paediatric assessments and the taking of forensic samples to confirm that they had been given illicit substances. The children had been placed on the area child protection register 8 months earlier under the category of neglect, shortly after the younger child's birth. During this pregnancy the mother had taken drugs and her urine tested positive for cocaine and cannabis. The birth was by caesarean section after an antepartum haemorrhage, a known complication of drug use in pregnancy. Soon after birth the girl was observed to be jittery, exhibiting mild features of drug withdrawal.

The children were seen by $A B$, a paediatrician with expertise in forensic medicine, five days after their last contact with the parents. The boy showed normal physical and social development, consistent with the history that his mother was drug free until he was 2 years old. The baby girl was strikingly physically active and the foster mother had made the same observation, which is frequent in babies born to drug-abusing mothers. In view of the delay between removal of the children from the parental home and the clinical assessments, urine and blood samples were thought unlikely to give positive results and were thus not taken. Hair specimens were taken from each child's crown

${ }^{1}$ Department of Paediatrics, Northwick Park Hospital NHS Trust, Watford Road, Harrow, Middlesex HA1 3UJ; ${ }^{2}$ Forensic Medical Examiner, London Metropolitan Police, UK according to the protocol of the company concerned (Tricho-Tech, Cardiff). The special packaging was sealed and labelled to ensure continuity of evidence. The results, received within a few weeks, were positive for methadone in both children, who were then permanently removed from their parents' care and subsequently adopted.

\section{COMMENT}

Hair analysis can be employed to detect substances including opioids, benzodiazepines, barbiturates, amphetamines, cocaine and cannabis. The company used here, Tricho-Tech, screens specimens by enzyme-linked immunosorbent assay and does confirmation analyses by gas chromatography/mass spectrometry. In declared methadone users the specificity of hair analysis exceeds $99 \%$ (personal communication).

Methadone is a synthetic opioid prescribed in liquid form to adult substance abusers. In adults the drug and its metabolite are detectable in urine for about 2 days after a single oral dose; in children there are no published pharmacokinetic data. Children should not have methadone in their blood, urine or hair. In babies with neonatal drug withdrawal syndrome, analysis of hair, as well as other samples such as amniotic fluid, nails ${ }^{6,7}$ and urine, can confirm maternal drug use.

The Children Act requires proof of significant harm above a minimum threshold. Professionals aim to keep children within the family home. Assessments need to be done over a short period, since a child's development is rapid within the first few years of life. In the case reported here the use of forensic science provided objective evidence within a matter of weeks, allowing arrangements for care and nurturing outside the parental home. In cases of suspected child abuse, the child may be unable to give a history and the physical examination findings may be normal or non-specific. Professionals working in child protection often come under criticism, and such objective evidence can support their management. The results have medicolegal consequences, as with all forensic tests; therefore, hair analysis should not be used indiscriminately, and informed consent should be obtained. In child protection cases, the decision to obtain forensic samples should be based foremost on the child's best interests. ${ }^{8}$

Acknowledgments We thank the staff at Tricho-Tech for the hair analysis. Consent to publish this paper was given by the director of the local authority.

\section{REFERENCES}

1 Bartsch C, Risse M, Schütz H, Weigand N, Weiler G. Munchausen syndrome by proxy (MSBP): an extreme form of child abuse with a special forensic challenge. Forensic Sci Int 2003;137:147-51 
2 Lewis D, Moore C, Morrissey P, Leikin J. Determination of drug exposure using hair: application to child protective cases. Forensic Sci Int 1997;84:123-8

3 Strano Rossi S, Offidani C, Chiarotti M. Application of hair analysis to document coercive heroin administration to a child. J Anal Toxicol $1998 ; 22: 75-7$

4 Vinner C, Vignau J, Thibault D, et al. Hair analysis of opiates in mothers and newborns for evaluating opiate exposure during pregnancy. Forensic Sci Int 2003;133:57-62

5 Vinner E, Vignau J, Thibault D, et al. Neonatal hair analysis contribution to establishing a gestational drug exposure profile and predicting a withdrawal syndrome. Ther Drug Monit 2003;25:421-32

6 Skopp G, Pötsch L. A case report on drug screening of nail clippings to detect prenatal drug exposure. Ther Drug Monit 1997;19:386-9

7 American Academy of Pediatrics, Committee on Drugs. Transfer of drugs and other chemicals into human milk. Pediatrics 2001;108:776-89

8 The Children Act 1989. London: HM Stationery Office, 1989

\section{Neonatal pleural effusion and insertion of intercostal drain into the liver}

\author{
M J Murray MA MRCPCH ${ }^{1} \quad J$ L Brain MS FRCS ${ }^{2}$ \\ J S Ahluwalia FRCP FRCPCH ${ }^{1}$
}

J R Soc Med 2005;98:319-320

When a congenital diaphragmatic hernia $(\mathrm{CDH})$ is leftsided, radiographic diagnosis is usually straightforward. Right-sided $\mathrm{CDH}$ is clinically and radiographically more difficult.

\section{CASE HISTORY}

Dichorionic twins, a girl (twin 1) and a boy (twin 2), were born at 37 weeks by emergency caesarean section for prolonged rupture of membranes and fetal tachycardia in twin 1 . At first they were in good condition but at ten hours of age twin 2 developed signs of respiratory distress with mild hypercapnia $\left(\mathrm{pCO}_{2} \quad 7-8 \mathrm{kPa}\right)$ but no significant acidosis. A chest radiograph showed infiltrative changes in the right middle and lower lobes with the diaphragm apparently normal (Figure 1). Because the infant was irritable on handling, lumbar puncture was performed in addition to a partial sepsis screen. Antibiotics were given and the respiratory distress settled in forty-eight hours

Departments of ${ }^{1}$ Neonatology and ${ }^{2}$ Paediatric Surgery, Addenbrooke's Hospital Cambridge, UK

Correspondence to: Dr J S Ahluwalia, Neonatal Intensive Care Unit, Box 226, Addenbrooke's Hospital, Hills Road, Cambridge CB2 2SW, UK

E-mail: jag.ahluwalia@addenbrookes.nhs.uk without respiratory support. C-reactive protein peaked at $89 \mathrm{mg} / \mathrm{L}$ on day 4 and was normal by day 7 ; all cultures were subsequently reported negative. Twin 1 , who likewise received antibiotics, had a raised $\mathrm{C}$-reactive protein and group B streptococcus was grown from surface swabs.

On day 9 twin 2 became severely distressed with tachypnoea and a respiratory acidosis $\left(\mathrm{pCO}_{2} 10 \mathrm{kPa}\right)$. The chest radiograph (Figure 2) showed complete opacification of the right hemithorax consistent with a pleural effusion. In addition the nasogastric tube was noted to deviate to the left at the level of the mid-oesophagus. The infant was placed on continuous positive airway pressure with supplemental oxygen. An intercostal drain was inserted at the fourth intercostal space in the mid-axillary line and $27 \mathrm{~mL}$ clear serous fluid was obtained. When the drain ceased to show respiratory swings but clinical signs persisted, $20 \mathrm{~mL}$ of clear fluid was removed by thoracocentesis. The chest radiograph now revealed a liver shadow and bowel gas in the right hemithorax (Figure 2). An ultrasound scan, likewise indicating that the liver was in the right hemithorax, suggested that the intercostal drain was embedded in the right lobe of the liver. The infant was then transferred to the regional neonatal surgical centre with the chest drain in situ. On arrival he was intubated and mechanically ventilated. CT confirmed that the intercostal

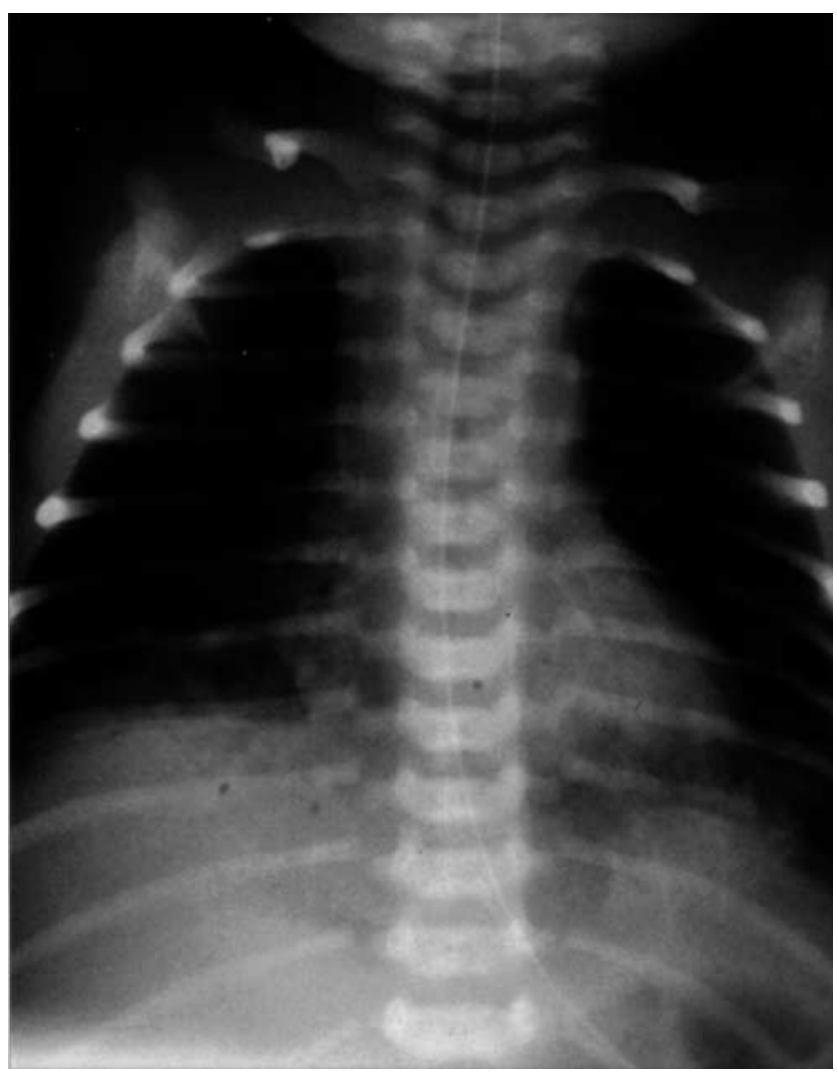

Figure 1 Initial chest radiograph showing infiltrative changes in the right middle and lower lobes with normal diaphragmatic appearance 